\title{
PRÁCTICAS DE EXPLORACIÓN Y COLONIZACIÓN. RELATOS DE MAURICIO JESPERSON SOBRE EL GRAN CHACO DURANTE LA PRIMERA MITAD DEL SIGLO XX
}

\author{
Exploration and colonization practices. Mauricio Jesperson's narratives about \\ the Gran Chaco during the first half of the 20th century
}

Anne Gustavsson*

\section{Resumen}

El objetivo de este artículo es brindar un primer acercamiento a la vida y las obras de Mauricio Jesperson (1888-1969), explorador y colonizador del Gran Chaco, nacido en Suecia quien llegó a la Argentina en 1913 con 25 años. La figura de Jesperson y su rol en la colonización del Gran Chaco, han pasado desapercibidos en la historiografía sobre esta región. El artículo presenta y analiza dos tipos de documentación, una selección de documentos del fondo Jesperson alojado en la biblioteca de la Universidad de Lund y algunas de sus obras publicadas durante su estadía en Suecia en la década de 1940. La mayoría de las fuentes tanto editas como inéditas están en sueco. Nos ocupamos principalmente de sus relatos sobre las relaciones interétnicas en zonas de frontera en el Chaco Austral y sobre las prácticas de colonización llevadas a cabo en estas zonas en el Chaco Boreal.

En este trabajo destaco que sus publicaciones constituyen valiosas fuentes históricas que no solo nos hablan de formas convencionales de representar el territorio y su población sino que también pueden contribuir a discutir las imágenes que emergen en los escritos a partir de la praxis y la experiencia del autor en el territorio. Se trata de narraciones acerca de los conflictos y la vida cotidiana en la frontera, a la vez que, de prácticas de colonización hasta el momento no abordadas por la historiografía, especialmente en lo que concierne la avanzada del Estado boliviano sobre el Pilcomayo en cuanto a políticas de colonización antes de la Guerra del Chaco.

$<$ Gran Chaco $><$ Mauricio Jesperson $><$ Colonización $><$ Frontera $>$

\begin{abstract}
The aim of this article is to provide a first approach to the life and works of Mauricio Jesperson (1888-1969), explorer and colonizer of Gran Chaco who was born in Sweden and arrived to Argentina in 1913 at the age of 25. The figure of Jesperson and his role in the colonization of the Great Chaco have gone unnoticed in the historiography of this region. The article presents and analyzes two types of documentation; a selection of documents from the Jesperson archival fund kept at Lund University's library and some of his published works which were written during his stay in Sweden in the 1940s. Most of the published and unpublished sources are in Swedish. We deal mainly with his accounts of inter-ethnic relations in frontier areas in Southern Chaco as well as colonization practices in this type of areas in Northern Chaco.

In this work I emphasize that these publications are valuable historical sources that not only shed light upon the conventional forms of representing the territory and its population but also contribute to

* Docente y doctoranda en Antropología Social, Instituto de Altos Estudios Sociales (IDAES), Universidad Nacional de San Martín. anne.gustavsson@gmail.com
\end{abstract}


a better understanding of the images which emerge as a result of certain practices in the territory. These narratives deal with conflicts and daily life on the frontier, as well as, some aspects of colonization practices until this moment looked over by historiography, especially in what concerns the advance of the Bolivian State on the Pilcomayo and its colonization policies before the Chaco War.

$<$ Gran Chaco $><$ Mauricio Jesperson $><$ Colonization $><$ Frontier $>$

Recibido: 28/09/2016 //Aceptado: 20/12/2016

\section{Introducción}

Cuando el transitar también es habitar. A continuación, presento y discuto algunos relatos escritos por un extranjero, colonizador y habitante del Gran Chaco ${ }^{1}$ en tanto narraciones, registros y conocimientos adquiridos en terreno a través de años de contacto constante con el suelo, los caballos, los pozos de agua, el ganado, las temperaturas extremas, el monte, la población criolla e indígena, los militares de los fortines de frontera y los compatriotas acomodados que habitaban en suelo sudamericano, entre otros.

El objetivo de este artículo es ofrecer un primer acercamiento a la vida y las obras de Mauricio Jesperson (1888-1969), explorador y colonizador del Gran Chaco, nacido en Suecia, llegó a la Argentina en 1913 con 25 años. La figura de Jesperson y su rol en la colonización del Gran Chaco han pasado desapercibidos en la historiografía sobre el Chaco. Solo existen algunos estudios recientes sobre su participación en la expedición de Haeger de 1920 y en la producción y edición del film Tras los senderos indios del Río Pilcomayo (Gustavsson y Giordano 2012, 2013, Giordano y Gustavsson 2013). Un antecedente interesante a mencionar para considerar la lectura actual de las obras editas de Jesperson y el interés en su persona en Suecia es la novela documental Caballero publicada en 1991 por la escritora Lise Drougge en la cual reconstruye la biografía de este autor combinando recursos ficcionales y documentales libremente sin mencionar las fuentes en las cuales se basa.

Vale mencionar que este análisis de la vida y fuentes de Jesperson se vincula a mi investigación doctoral sobre Imagen fílmica, etnografia y colonización del Chaco argentino. Historias y memorias de los pilagás y criollos en el departamento de Patiño, Formosa en la cual busco, entre otras cosas, comprender las condiciones históricas, sociales y culturales que posibilitaron la realización de la expedición científica comercial de Haeger de 1920 al Río Pilcomayo, cuyo guía fue Mauricio Jesperson.

El artículo presenta y analiza dos tipos de documentación, una selección de documentos del fondo Jesperson alojado en la biblioteca de la Universidad de Lund ${ }^{2}$ y

1 En términos geográficos, el Gran Chaco es considerado una amplia llanura semi-árida, casi en su totalidad, que se extiende desde los Andes hasta los ríos Paraguay y Paraná y desde la pampa hasta el sudeste de Bolivia.

2 El fondo titulado "Jespersons efterlämnade papper" fue adquirido por la biblioteca de la Universidad de Lund, Suecia recién en 2006 y se encuentra desde entonces abierto a la consulta pública. El fondo contiene fotografías, diapositivas, mapas, postales, correspondencia en sueco, castellano y alemán, 
algunas de sus obras publicadas durante su estadía en Suecia en la década de 1940: En Lundensare i Chaco (Un nativo de Lund en Chaco) de 1941, En Svensk Caballero vid Pilcomayo (Un caballero sueco a orillas del Pilcomayo) de 1942, el capítulo "Indianliv" (Vida indígena) en la compilación Chacofarare berätta (Cuentan los viajeros del Chaco) de 1943 editada por Curt Munthe, y I Vildmarkens Våld ${ }^{3}$ (Bajo el dominio del Desierto) también de 1943. La mayoría de las fuentes tanto editas como inéditas están en sueco. Cabe mencionar que todas las citas textuales de las obras de Jesperson de este artículo fueron traducidas del sueco al castellano por la autora. Salvo el capítulo "Indianliv", que ofrece una descripción documental y etnográfica de los pilagá, los demás relatos publicados constituyen narrativas literarias basadas en las experiencias de vida de Jesperson en el Chaco austral y boreal durante las dos primeras décadas del siglo XX. Aunque estos relatos, en cuanto basados en sus memorias, fueron elaborados desde una distancia temporal y espacial y presentan una versión un tanto romantizada de su vida donde predomina como motor de una serie de "aventuras" su afán por lo desconocido, en este trabajo destaco que constituyen valiosas fuentes históricas que no solo nos hablan de formas convencionales de representar el territorio y su población sino que también pueden contribuir a discutir las imágenes que emergen en los escritos a partir de la praxis y la experiencia del autor en el territorio. Se trata de narraciones acerca de los conflictos y la vida cotidiana en la frontera y, a la vez, de prácticas de colonización hasta el momento no abordadas por la historiografía, especialmente en lo que concierne la avanzada del Estado boliviano sobre el Pilcomayo en cuanto a políticas de colonización antes de la Guerra del Chaco.

Con respecto a cómo analizar las narraciones históricas concuerdo con Ginzburg (2010) quien sostiene que éstas no nos hablarían de la realidad tanto como de quien las construyó pero argumenta que si se indaga en el interior de los textos, a contrapelo de las intenciones de quien los produjo, pueden sacarse a la luz voces no controladas. Es decir, trata a las fuentes y producciones sobre la historia como narraciones subjetivas impregnadas de historia. En nuestro caso, los relatos nos proporcionan imágenes concretas, huellas impregnadas de la experiencia vivida en el territorio.

\section{Don Mauricio Jesperson. Explorador y colonizador del Gran Chaco}

A lo largo de su vida Jesperson se dedicó a estudiar el territorio chaqueño, su población y características ambientales, volviéndose especialista en materia de colonización de tierras en el Chaco boreal que muchos consideraban improductivas. A su llegada a la Argentina en 1913 Jesperson primero trabajó en una estancia en el noroeste de la provincia de Santa Fe, luego participó en varias expediciones de reconocimiento

manuscritos, cuadernos de campo y libros. Parte del rastreo y relevamiento del material de archivo fue realizado gracias a la colaboración de Mariana Giordano.

3 Una edición posterior y más corta del libro En Lundensare i Chaco de 1941 que no incluye los primeros capítulos sobre la época de Jesperson en Monte Carlo y como se hace marinero en el puerto de Genova, Italia. 
territorial en el Chaco Central y Boreal ${ }^{4}$ entre 1916-1920, hasta establecer su propia estancia y plantación de algodón "Campo Luminoso", en 1921, en las cercanías de Las Lomitas, en el entonces Territorio Nacional de Formosa. Salvo el caso de la expedición de Haeger de 1920 a la zona de los Esteros de Patiño y el Río Pilcomayo, contamos con muy poca información sobre las demás empresas; una expedición en 1915 a los "matacos" del río Teuco en el Chaco Austral; otra en 1916 a los "chunupis" del Río Pilcomayo en el Chaco Central, en 1917 de nuevo al Chaco Central pero esta vez a los tobas del río Bermejo, en 1918 al Estero Patiño para conocer a los pilagá y finalmente durante los años 1919 y 1920 a las partes interiores del Chaco boreal ${ }^{5}$. El objetivo de una de estas últimas era ver la viabilidad de las tierras al norte del Pilcomayo para una posible colonización por parte de los alemanes que huían de las consecuencias de la primera guerra mundial. Gracias a los estudios acerca de la viabilidad de la colonización de esta última zona, fue contratado entre 1922 y 1933 por una firma porteña para colonizar un millón de hectáreas al norte del Río Pilcomayo en lo que algunos consideraban en aquel entonces territorio boliviano. Un área que en realidad formaba parte del territorio que estaba en disputa entre Bolivia y Paraguay, conflicto que desató la Guerra del Chaco (1932-1935). El proyecto de colonización y lo construido por los colonos fue arrasado por la guerra. Una derrota que llevo a Jesperson a volver a su país natal. Se radicó en Estocolmo donde se dedicó a diversos negocios, por ejemplo, importó yerba mate a Suecia desde Argentina ${ }^{6}$. En la década de 1940 escribió y publicó las memorias de sus experiencias en el Gran Chaco en formato de relatos de aventura para un público amplio y participó activamente en la fundación de una asociación civil titulada Asociación de los Viajeros suecos al Chaco cuyas actividades incluían el proyecto editorial Chacofarare Berätta (Cuentan los viajeros del Chaco), la organización de charlas sobre el Gran Chaco para un público amplio, proyectos de exhibiciones sobre el Gran Chaco en colaboración con el Museo Etnográfico de Estocolmo, y la edición y el estreno del film Tras los senderos indios del Río Pilcomayo realizado con el material fílmico y fotográfico de la expedición científica comercial de Haeger al Pilcomayo en 19207. Luego de un período de 16 años retornó a América del Sur donde lo esperaban nuevos desafíos de colonización, esta vez en el departamento de Beni en las tierras bajas de Bolivia. En 1969 fallece en Cochabamba. En este artículo nos ocuparemos principalmente de sus relatos sobre las relaciones interétnicas en zonas de frontera en el Chaco Austral y sus prácticas de colonización en estas zonas en el Chaco Boreal.

${ }^{4}$ El Chaco Boreal se encuentra al norte del Pilcomayo, y el Chaco Central, en su sur, en las argentinas provincias de Formosa y porción de Salta.

5 De esta manera describe sus expediciones el mismo Jesperson en dos publicaciones tituladas "¿Quién es quién?" y "Escanéses en Estocolmo" que contiene breves resúmenes de los logros de diferentes personalidades de la época; Anónimo, 1945. "Jesperson, Mauricio" En Harnesk, P. (Ed.). Vem är vem? Stockholms delen Vem är Vem Bokförlag, Stockholm; Anonimo. 1940. "Mauricio Jesperson" En: Skåningar i Stockholm Skånetryckeriet Malmö.

6 Existe correspondencia y otra documentación relacionada a la importación de yerba mate en el fondo Jesperson, biblioteca de la Universidad de Lund.

7 Existen algunos documentos relacionados a la gestión de esta asociación en el archivo de Världskulturmuseet (ex Museo Etnográfico de Gotemburgo), ver donación de Gunnar Haeger de 1977 relacionado a la expedición de su hermano Gustav Emil Haeger al Pilcomayo de 1920. 
Sabemos que nació el 29 de 1888 en Escania, en el sur de Suecia, con el nombre de Mauritz Nilsson y que en algún momento de su juventud tomó el apellido de su abuelo paterno que se llamaba Nils Jesperson. Accedió a estudiar en la Universidad de Lund. Según cuenta al comienza de sus dos autobiografías (Jesperson 1941 y 1942), en uno de sus viajes a la costa azul en 1912 terminó en bancarrota en el casino de Monte Carlo y en lugar de volver sin un centavo a Suecia eligió probar suerte como ayudante de cocina a bordo del buque Berlin de 18000 toneladas que zarpaba de Genova con destino a Sydney. A la vuelta de Australia y de las islas del Pacífico sur, su intención era unirse al servicio colonial en las Indias Orientales Holandesas, pero el consulado sueco en Amsterdam le recomendó otro destino más prometedor, la Argentina. En agosto de 1913 luego de haber cumplido un año de servicio como marinero a bordo del transatlántico Hollandia arriba al puerto de Buenos Aires. A pesar de encontrarse con varios compatriotas suecos con buenas posiciones sociales en Buenos Aires todos se negaron a contratarlo a causa de la profunda crisis que estaba padeciendo el país. Razón por la cual prueba su suerte subiendo a un tren que lo lleva hasta Huanqueros, provincia de Santa Fe. Una vez llegado a la Argentina adopta el nombre Mauricio, la versión en castellano de Mauritz.

\section{Circulación del conocimiento sobre el Chaco en sueco}

Jesperson escribía perfectamente en castellano pero decidió publicar sus libros sobre el Chaco en sueco. Sus narrativas literarias sobre sus propias prácticas de explorar y colonizar en el Gran Chaco se sitúan dentro de una circulación más amplia de conocimiento e informaciones en sueco sobre este territorio y su población indígena que nos hablaría de un interés particular de parte del público lector sueco por estos temas. A lo largo del siglo XX se publicaron una amplia gama de escritos específicamente en sueco sobre esta región desde intereses y emisarios diversos. Circulación de datos que se inaugura a partir de la labor científica de Erland Nordenskiöld quien entra en contacto con los indígenas chaqueños durante la expedición Chaco-Cordillera de 1901-1902, y quien posteriormente realiza varias expediciones al Chaco central y boreal para dedicarse exclusivamente al estudio etnográfico y etnológico de sus pueblos indígenas. Decide publicar no solo monografías y artículos en varios idiomas para la comunidad científica internacional sino también relatos literarios sobre sus expediciones para un público amplio en Suecia ${ }^{8}$. Entonces, en primer lugar tenemos las publicaciones científicas y literarias ${ }^{9}$ relacionadas con la expedición Chaco-cordillera y con el establecimiento de la Escuela de Nordenskiöld en Gotemburgo a partir de la década de 1910 (Lindberg, 1996).

En segundo lugar, existen publicaciones como las de Jesperson (1942, 1943 [1941]) y la compilación de Munthe (1943) que se relacionan con experiencias de

8 Vease Nordenskiöld, E. 1926 (1910) Indianliv i El Gran Chaco, Sydamerika.Stockholm: Åhlén \& Åkerlunds

9 Vease por ejemplo Rosen, E. v. 1921. Bland indianer, Forskningar och äventyr i Gran Chaco Stockholm: Albert Bonniers förlag; Rydén, S. 1936. Chaco. En resa bland fornlämningar och Indianer i argentinska och bolivianska Chaco. Göteborg: Förlag- aktiebolaget Västra Sverige. 
radicación y proyectos productivos. Jesperson consideraba que formaba parte de una tradición de exploración del Chaco en el cual sus compatriotas habían tenido un rol central. Junto a otros conocedores de esta región vinculados a la Asociación de Viajeros suecos al Chaco se dedica en la década de 1940 a construir y dar a conocer una genealogía de exploración sueca en esta región en la cual se da un lugar destacado a sí mismo, incorporando también otras figuras dejadas afuera por las tradiciones científicas en Suecia y Argentina y la antropología del Chaco en general.

Finalmente, tenemos publicaciones destinadas a un público general que rescatan la vida y los relatos de los misioneros pentecostales suecos que se dedicaron durante gran parte del siglo XX a evangelizar al pueblo wichí en la zona de Villa Montes en Bolivia $^{10}$. Los primeros misioneros llegaron desde Suecia a Embarcación en el norte de Argentina en 1920 donde el misionero noruego Birger Johnsen ${ }^{11}$ los recibió y orientó durante el primer tiempo (Alvarsson 2002). Según Alvarsson (2002) los jóvenes misioneros se habían inspirado en los libros de Nordenskiöld a través de los cuales obtuvieron información sobre la localización y estado "primitivo" de los indígenas del Chaco argentino y boliviano. Luego de establecer una misión en Orán, viajaron a Bolivia donde primero se establecieron en Cochabamba y luego en Santa Cruz de la Sierra y desde la década 1940 concentraron la labor de evangelización en Villa Montes (Alvarsson, 2002).

Asimismo queda pendiente seguir indagando y profundizando en el conocimiento sobre la circulación y apropiación de información específicamente escrita en sueco sobre el territorio chaqueño y su población durante la primera mitad del siglo XX por parte de científicos, misioneros y colonizadores/exploradores oriundos de aquel país nórdico. También sería interesante indagar en el funcionamiento de redes de ayuda mutua entre, por un lado, misioneros y científicos escandinavos en la realización de sus proyectos en el Chaco y, por otro lado, entre éstos y residentes suecos en Argentina y Bolivia con diferentes posiciones sociales, dedicados a distintas actividades y emprendimientos económicos.

\section{Colonización y zonas de frontera en el Gran Chaco}

Si seguimos el recorrido geográfico por el cual transita Jesperson durante su vida notamos que el ambiente que lo atrae, en el cual se mueve, en el cual parece estar a gusto, al cual vuelve luego de una estadía de 16 años en su tierra natal Suecia, es el de la frontera. En este trabajo el concepto de frontera tiene un doble sentido; por un lado, una zona de contacto donde interactúan diferentes actores con los "otros internos" establecidos dentro de cada Estado Nación (Briones, 2005) y por el otro, como limite geopolítico negociado entre los Estados naciones, en nuestro caso interesan

${ }^{10}$ Vease por ejemplo Anderås, P. 1961. Boliviafarana berätta, Örebro: Evangelipress; Kung, A. (1977) Boliviafarna. Stockholm: Normans bokförlag; Alvarsson, J.-A. 1982. Indianeld. Avesta: A.B.M. - tryck AB; Alvarsson, J.-Å. 2002. "Till Bolivias indianer...” Berättelsen om Svensk Pingstmission $i$ "Sydamerikas skogstrakter". Örebro: MissionsInstitutet-PMU och Pingströrelsens Informationscentrum.

11 Johnsen fundó la Misión Escandinava en Embarcación en 1914. Sobre la historia de esta misión consultar Cernadas, C. C. 2011. La misión pentecostal escandinava en el Chaco argentino. Etapa formativa: 1914 - 1945. Memoria americana 19 (1). 
particularmente los de Paraguay, Bolivia y Argentina. En el primer sentido del término, buscamos superar el concepto tradicional y etnocéntrico de "frontera" como límite rígido que divide los espacios conquistados de aquellos no conquistados (Boccara, 2001), rescatando la dimensión contactista de estas zonas poniendo en primer plano los aspectos interactivos e imprevistos y la constitución de individuos a través de relaciones mutuas en estos espacios sociales donde culturas dispares se encuentran, chocan y se enfrentan, a menudo dentro de relaciones altamente asimétricas de dominación y subordinación (Pratt, 2011).

Jesperson lleva a cabo sus prácticas de reconocimiento y colonización en estas zonas de "frontera", donde se dan interacciones diversas y/o asimétricas entre diferentes actores en terreno que indican la existencia de varias situaciones de posconquista en el Gran Chaco. Al mismo tiempo hay intereses geopolíticos concretos que inciden en esos espacios. Se puede entonces entender estas prácticas en términos de una justificación y acompañamiento al proceso del despojo de los indígenas de sus territorios, llevado a cabo militarmente por los gobiernos nacionales y/o por otros actores. En el caso del chaco argentino, la ofensiva militar organizada desde el gobierno nacional contra los indígenas se conoce en la historiografía como la conquista del Chaco. Aunque la campaña de Rostagno de 1911 es considerada el último gran avance militar contra las comunidades indígenas sabemos que posterior a esta fecha el Estado aún no tenía un dominio total del territorio ocupado, especialmente en la zona del Pilcomayo del medio (Gordillo, 2001; Bossert y Silfredi, 2011) pero también en áreas interiores y alejados de los ríos Bermejo y Paraná en el Territorio Nacional del Chaco (Beck, 1994). Para el Chaco boreal, las iniciativas de avance sobre los territorios indígenas desde Asunción nunca tuvieron una fase militar sistemática como en el caso argentino, sino que la penetración, control y uso de los recursos fue directamente relegado a compañías extranjeras y misiones religiosas (Dalla Corte y Vazquez Recalde, 2011). En el caso de Bolivia, la construcción de fortines sobre la ribera norte del Pilcomayo a comienzos del siglo XX y luego la instalación de misiones religiosas en la década de 1920 fue más una estrategia para marcar el avance sobre el territorio en disputa con Paraguay y un intento de convertir a los indígenas en simpatizantes bolivianos que parte de un avance sistemático sobre el territorio indígena (Fritz, 1997 y 1999; García Jordán, 2001; Morel, 2015). Sin embargo, una vez que se produce la guerra del Chaco sí hay una efectiva ocupación de grandes extensiones del territorio indígena. Como señala Richard (2008) esta guerra no solo constó de un conflicto entre Estados sino que también funcionó como una campaña de ocupación militar del espacio indígena.

\section{Militares, colonos, gauchos e indígenas en el noroeste del Chaco Austral a principios del siglo XX}

A continuación y con el objetivo de presentar algunos relatos y descripciones que hace Jesperson de las relaciones y conflictos existentes entre mocovies ${ }^{12}$, colonos,

${ }^{12}$ El pueblo indígena mocoví pertenece al complejo lingüístico y cultural guaycurú, conformado históricamente por los grupos toba, pilagá, abipón, kadiweu, payaguá y mbayá, todos de tradición 
"gauchos", y soldados del $6^{\circ}$ Regimiento de Caballería en el Chaco santafesino durante la década de 1910, nos basaremos principalmente en el libro I vildmarkens våld, publicado en 1943, debido a la falta de material de archivo sobre esta época de su vida.

Tanto durante la época colonial como republicana existió una preocupación desde los poderes gobernantes por contener e incorporar a los mocovíes, como a otros grupos chaqueños, a la sociedad hegemónica. Con la fundación de las reducciones mocoví San Javier y San Pedro por parte de los jesuitas en el siglo XVIII comienza la evangelización católica de este pueblo indígena, promoviendo de esta manera su sedentarización e introduciendo creencias y rituales católicos y nuevas prácticas de subsistencia (Citro, 2006). En el siglo XIX estas reducciones siguieron funcionando bajo el mando de los Franciscanos, a los cuales se sumaron varias misiones nuevas ${ }^{13}$. Durante el periodo colonial, una de las transformaciones socioculturales más importantes para esta sociedad indígena fue producida por la incorporación del caballo en el siglo XVII. A partir del siglo XVIII tanto los indígenas "reducidos" como "montaraces", así denominados por permanecer en el monte, formaron parte de redes comerciales establecidas con diversos sectores de la sociedad, especialmente con el fin de la apropiación e intercambio de ganado vacuno y caballar (Citro, 2006). A partir de la mitad del siglo XIX se suman al proceso de evangelización como complementario al sometimiento de los indígenas, por un lado, el avance militar sistemático sobre el territorio chaqueño, comenzado por Obligado en 1872 y continuado por el Ministro de Guerra y Marina Victorica en 1884 hasta alcanzar el Río Bermejo, y, por el otro, la promoción de la inmigración y de la colonización, inaugurada con la fundación de Colonia Esperanza en 1856 (Dosztal, 2016; Spota, 2009). Tanto las colonias como posteriormente las industrias, obrajes de extracción de tanino como ingenios, que comenzaron a instalarse en el Norte de Santa Fe a partir de 1880 se establecieron estratégicamente sobre o en la cercanía del Río Paraná, un área claramente atractiva por su buena comunicación y posibilidades de comercio con el resto del país y el mundo. ¿Qué ocurre con las tierras santafesinas que se encuentran alejadas de los principales accesos fluviales durante esta época y las primeras décadas del siglo XX? ¿Por ejemplo, las del noroeste de Santa Fe, próximas a los límites con Santiago de Estero en el oeste y el territorio Nacional del Chaco al norte? Hasta el momento no hemos encontrado bibliografía sobre la colonización de esta región para este periodo. Sin embargo, gracias a las investigaciónes de Lopez (2009) y Altman (2011) sabemos que a fines del siglo XIX y principios del siglo XX, el avance de colonos desde Santa Fe hacia el norte provocó el desplazamiento de muchos mocoví a zonas del sur de la actual provincia del Chaco, que se encuentra muy cercano al área donde transcurren los acontecimientos narrados por Jesperson. Los relatos de Jesperson nos ofrecen miradas y datos sobre esta otra zona de frontera y colonización de Santa

cazadora-recolectora. El Chaco Austral, es decir, las actuales provincias argentinas de Chaco y Santa Fe, ha sido el hábitat originario de tanto los mocoví como los abipón. En los textos de Jesperson aparecen bajo la denominación "mocobi" que traducimos a mocoví.

${ }^{13}$ Se trata de las reducciones franciscanas Calchines y San Pedrito de 1833, Cayastá de 1860, Nuestra Señora de Dolores de 1870, Purísima Concepción de Reconquista en 1872 y San Antonio en 1883 (Citro 2006). 
Fe, donde para 1913 existían todavía pocos poblados y donde prevalecían las estancias basadas en la ganadería vacuna.

Durante sus primeros años en Argentina (1913-1916) Jesperson aprende las tareas de los peones y trabajadores rurales en una estancia dedicada a la ganadería vacuna llamada El Mogote de 20000 hectáreas, arrendado por un tal Guillermo Schultz, ubicada en el norte de la provincia de Santa Fe a aproximadamente $100 \mathrm{~km}$ al norte de Huanqueros en el Chaco austral. Sobre la historia de esos campos arrendados por Schultz que anteriormente a 1913 formaban parte de un latifundio conocido bajo el nombre "La Blanca", Jesperson cuenta lo siguiente:

"Toda la tierra por la cual hemos transitado hoy y la que se extiende hacia el norte si seguimos viajando un día más, se vendió por el gobierno a una empresa franco-inglesa con sus directivos en Paris hace muchos años ya. El gobierno de Santa Fe quería sacarse de encima esa tierra, por su difícil colonización debido a la falta de agua potable y la poca fertilidad de su tierra. Además, esta tierra desértica conducía directamente a Santa Fe, ciudad capital de la provincia, a la cual los indios mocovíes contendientes amenazaron más de una vez. Durante la época de lluvias, millares de indios mocovíes se reunían allí y se efectúan malones constantemente a los parajes de las cercanías. Por lo tanto, el gobierno provincial vio en la venta de estas tierras un excelente negocio (...) Desde París se dividió todo el área como si fuese un tablero de ajedrez y en el centro de cada cuadrado se marcó el sitio para un gran aljibe con motor a viento. Por otra parte, había que construir un puesto para el puestero - protector del ganado -, así como amplios corrales para el ganado. Una gran cantidad de gauchos fueron contratados para ahuyentar a los indios y proteger a los trabajadores, quienes alambraban cada cuadrado. Era una obra gigante que requirió del trabajo de cientos de hombres. Los viejos criollos consideraban las disposiciones desde París completamente irrazonables, pero las órdenes eran inmutables y el director ejecutivo francés debía seguirlas estrictamente. Como consecuencia solo salía agua salada y amarga de los pozos cavados, y los cientos de miles de vacas, que se introdujeron en estos campos, murieron, en gran parte de sed" (Jesperson, 1943:17-18)

La adquisición de tierras y el proyecto productivo de ganadería que describe Jesperson se ubica temporalmente en algún momento antes de su llegada a la zona en 1913, probablemente a fines del siglo XIX. Debemos tener en cuenta que en la Provincia de Santa Fe, entre 1870 y 1895 se lleva a cabo el proceso denominado colonización privada, en el cual el rol del Estado es fuertemente reducido, en comparación con el 
periodo anterior denominado colonización oficial. En esta fase privada el empresario es eximido del pago del impuesto de contribución directa si las tierras se encontraban fuera de la línea de frontera y si en éstas se desarrollaban actividades comerciales e industriales, sin tener que asumir el compromiso de poblar las tierras con colonos (Dosztal, 2016).

Quiero subrayar aquí la crítica que realiza Jesperson a este emprendimiento europeo manejado desde la distancia de París sin tener en consideración el conocimiento local de los antiguos criollos que habitaban y conocían el territorio. Es interesante resaltar que los "indios", quienes serían los más antiguos habitantes del territorio, no eran considerados por Jesperson en estos términos. A diferencia de los criollos o gauchos, los "indios" carecerían de conocimiento específico sobre cómo llevar a cabo proyectos productivos en un entorno como el chaqueño. Con respecto a los indígenas, aunque a veces resalta su inteligencia y astucia, reproduce el discurso dominante sobre su belicosidad considerando a sus "malones" como un obstáculo para los avances del progreso y la productividad de las tierras en lugar de una respuesta o resistencia al sistemático despojo de sus territorios ancestrales en los cuales antes de la conquista podían llevar a cabo sus prácticas tradicionales de subsistencias (Tamagno, 2001 en Greca, 2009). A lo largo del libro tanto la población criolla como los denominados "gauchos" son positivamente valorizados mientras continuamente describe a algunos "gringos", europeos o descendientes de europeos, incluyéndose a sí mismo, y a la mayoría de los militares como personas que debían aprender de los anteriores para sobrevivir en el Chaco.

Para Jesperson el gaucho era una especie de baqueano con un conocimiento territorial excelente quien, a diferencia de los militares, sabía localizar fuentes de agua dulce, era un domador y cazador habilidoso y que en algunos casos hablaba lenguas indígenas. Así describe Jesperson a los "gauchos", a quienes consideraba que pertenecían a una categoría social existente en el Chaco austral en 1913 y con los cuales pareciera identificarse:

"En el sur de Chaco había muchos hombres que vivían la vida libre de los gauchos. A veces trabajaban en alguna estancia, como domadores de caballos o guardianes del ganado, pero sólo por un tiempo limitado. De lo contrario, deambulaban por ahí cazando y capturaron incluso algún ganado vuelto salvaje al cual domaban para luego conducirlo a las zonas habitadas donde eran vendidos. Tenían una predilección por recorrer el desierto, cuyas zonas desconocidas los atraían, motivándolos a emprender viajes de exploración y empresas llenas de aventuras (Jesperson, 1943:28)".

Como hemos señalado en otro trabajo (Giordano y Gustavsson, 2013), para comprender el valor atribuido al gaucho por Jesperson, debemos considerar que en la época en que llegó a la Argentina en 1913 -en el contexto del Centenario de la República- 
se difundía una mirada benévola a la vez que idílica especialmente sobre la figura del gaucho, que aparecía como emblema de lo nacional, tanto en las representaciones visuales como en la literatura gauchesca.

A tal punto admira y romantiza a los gauchos que convierte a uno de ellos en su co-protagonista, un viejo gaucho conocido bajo el nombre de Macua quien en varias ocasiones Jesperson nos presenta como su guía y mentor y quien cumple un rol clave en las mediaciones entre los diferentes actores de la sociedad blanca colonizadora y los líderes mocoví. La capacidad de negociar con ellos se debe a su conocimiento de la lengua indígena como de sus movimientos y la constante relocalización de sus paraderos.

"Una vez que se había terminado el trabajo de instalación, los directivos en París decidieron que el servicio de protección a cargo de los gauchos era superfluo, y que era necesario despedirlos por razones económicas. Macua, quien anteriormente había estado a cargo de la seguridad de La Blanca, partió a otro lugar, dando vía libre de nuevo a los indios. Éstos respetaban a Macua, con el cual preferían evitar entrar en guerra. Macua por su parte no temía la guerra, pero tampoco lo buscaba. Era un gran diplomático. Cuando los indios pasaban tiempos difíciles, les daba unas docenas de bueyes con el fin de convencerlos a desplazarse a otros territorios de caza. (...) Durante muchos años era difícil en La Blanca conseguir una noche de buen sueño. Pocas veces se había visto a una tribu india más experimentada y hábil en el robo de ganado vacuno que a estos persistentes y astutos mocoví. Aún cuando se construyeron corrales hechos con gruesas paredes de ladrillo y con portones fuertes de chapa de hierro y grandes candados, se realizaron robos de todos modos. Entonces, el gobierno intervino y envió el sexto regimiento de caballería para luchar contra los indios. Una gran parte de la población civil también se sumó. Los valientes mocoví lucharon como leones, pero las mejores armas hicieron de los militares y los civiles los vencedores. Los mocoví, quien contaban con veinte mil guerreros en el momento en que se estaban movilizando hacia la capital de Santa Fe, ahora se habían reducido a un tercio, pero sin embargo continuaban con sus asaltos (Jesperson, 1943:17-18).”

Aunque los sucesos arriba descritos no tienen fecha y año es interesante resaltar la descripción de la diversidad de actores que activamente participaban en la protección de las tierras colonizadas y las expediciones bélicas contra los indígenas: los gauchos contratados por las estancias o emprendimientos productivos como un tipo de guardia privada, la población civil que defendía sus familias y su propiedad, y el Estado a través 
de la instalación de fortines y la presencia militar en el territorio. Esto es algo que también veremos más adelante en las expediciones en las cuales participa Jesperson que tienen como objetivo recuperar ganado robado por los indígenas. Hay varios estudios que reconocen que el avance militar en el Chaco austral no fue realizado solo por las fuerzas gubernamentales sino también por los colonos extranjeros y por los grupos indígenas reducidos que colaboraban con el ejército, llamados los Cuerpos de Lanceros (Citro, 2006).

Recordemos que aunque la campaña de Victorica de 1884 había llevado la línea de fortines hasta el Bermejo esto no significaba que los territorios entre el Río Salado y éste fueron libres de indígenas (Beck 1994). De hecho, la Campaña del General Winter de 1899 no solo refuerza la línea de fortines sobre el Bermejo sino que dirige las tropas del Regimiento 6 y 11 desde los pueblos de Tostado y Reconquista en el Norte de Santa Fe hacia el interior del Territorio Nacional del Chaco, al sur del Río Bermejo.

Según Jesperson, la mayoría de los colonos y estancieros de la zona eran descendientes de inmigrantes suizos que habían llegado desde 1850. En 1913 cuando arriba a la estancia El Mogote, cuenta 8000 guerreros mocoví quienes a pesar de la presencia militar seguían robando ganado vacuno y caballar a lo largo del Río Salado desde Tacañitas en Santiago del Estero hasta Malabrigo a lado del Río Paraná, un recorrido de $700 \mathrm{~km}$. A continuación, trataremos la participación de Jesperson en dos expediciones que tienen como fin recuperar ganado robado por los mocoví.

En el primer caso, se suma a una expedición dirigida por el capitán Pedro Gómez de un escuadrón del sexto regimiento de Caballería con base en Tostado. El robo de los caballos tuvo lugar en un rancho ubicado a 80-100 km al noreste del Fortín Tostado en lo que Jesperson llama territorio mocoví. No revela la fecha y año del acontecimiento pero es probable que sea apenas llega al Chaco en 1913 por la mención del escuadrón de Tostado. Tengamos en cuenta que cuando se retira en 1911 el coronel O'Donell, quien había comandado la División de Caballería del Chaco, las tropas del regimiento 6 quedan con su grueso en Tostado, Santa Fe, y el resto repartido en los fortines ubicados en el extremo sur del territorio nacional de Chaco $^{14}$ (Beck 1994). Luego cuando Rostagno sucede a O'Donell a partir de 1911 el grueso del 6 regimiento de Caballería es trasladado de Tostado al km 177 del ferrocarril entre Barranqueras y Metán (Luego km 173 o Presidencia Roque Saenz Peña) (Beck, 1994). Consideramos que es posible que algún escuadrón se haya quedado en Tostado hasta 1913.

Desde el principio del relato, Jesperson resalta, por un lado, lo usual que eran los robos de ganado y, por el otro, incapacidad de los militares en su empresa de recuperar los caballos. Al encontrarse con las tropas, Jesperson les ayuda a encontrar agua y a rastrear los indígenas que se llevaron los caballos, conocimiento que Jesperson explícita viene de sus andanzas con el "gaucho" Macua. La expedición del capitán Gómez es presentada como un fracaso. No solo tiene dificultad en rastrear y recuperar los caballos extraviados sino que los mocovies logran robarle a su propia tropa todas las mulas.

${ }^{14}$ Se trata de los fortines Necochea, San Martin, Donovan, Brandsen, Aguilar, Pringles, Decarolli, Dorrego, Sargento Cabral, General Capdevila, y Teniente Pirís. 
Es importante destacar que todavía en 1911 queda pendiente el reconocimiento de grandes extensiones de Chaco; la inmensa zona que se extiende en su límite sur desde la estación La Sabana hasta la frontera con Santiago del Estero, y en el norte hasta el Pilcomayo entre Pichelé al este y las poblaciones de Tigre y Santiago al oeste de Laguna de los Pájaros (Beck, 1994). Es decir, había que nuevamente recorrer y reforzar algunas áreas donde ya habían avanzado anteriores campañas militares y donde existían fortines desde antes. Como señala Spota (2009) en su estudio sobre los fortines instalados en el Chaco entre 1862-1884, aunque el avance de la línea de éstos se utilizó como un instrumento de propaganda destinado a propulsar políticamente a sus autores intelectuales y materiales, en el terreno, los fortines pocas veces garantizaban el control del territorio y la protección de la población colonizadora. En este trabajo, por tratarse de la misma organización fortinera que estudia Spota pero durante un periodo posterior, consideramos que la situación de dificultad en el control territorial puede haberse extendido en el tiempo hasta el período de posconquista que estamos considerando aquí.

Por último, Jesperson critica las intenciones genocidas de un ataque sorpresivo de parte del capitán Gómez que al final no tiene éxito por haberse evacuado la aldea a tiempo.

"Gómez ordenó de inmediato que el pueblo sea atacado desde todos lados. También dio órdenes de que ninguno de sus habitantes masculinos se salvara... La orden de disparar a los varones también iba afectar a las mujeres. Incluso a plena luz del día era difícil distinguir el género de los indios a distancia y ahora con la iluminación engañosa del amanecer iba ser imposible determinar si se disparaba a un hombre o una mujer (...) Me lamentaba amargamente que le había mostrado la pista al capitán Gómez, pero no contaba en su momento con experiencia previa de la manera en la cual los militares trataban a los mocoví (Jesperson 1943:52)”.

A lo largo del libro Jesperson no cuestiona la legitimidad de las expediciones contra los indígenas pero sí la situación en la cual era justificable el uso de violencia. Esto nos habla de la moralidad de Jesperson a la vez que de las prácticas contra el indio que eran habituales y aceptables en diferentes círculos. Por ejemplo, matar a indígenas en un ataque para recuperar ganado robado era una práctica legítima tanto para Jesperson como para los militares, policías y la población civil que acompañaban y ayudaban a estos últimos en sus expediciones. Jesperson se diferencia en su posicionamiento moral con respecto a los militares cuando se trata de la utilización de violencia contra mujeres y niños y el exterminio de comunidades indígenas enteras, práctica que sabemos por la historiografía del Chaco que era común entre expediciones militares (Mapelman y Musante 2010). Como vemos a continuación, entre colonos y estancieros también era inaceptable torturar a un indígena varón considerado culpable por robo, salvo cuando se trataba de una venganza. 
La segunda expedición descripta por Jesperson, a la cual se sumó en agosto de 1914, era de carácter civil-policial integrada por 30 hombres, todos descendientes de suizos menos dos criollos y el propio Jesperson. La mayoría eran estancieros o hijos de estancieros afectados por los robos de ganado y contaban también con un "comisario de frontera" ${ }^{15}$. No hay mención de presencia militar. En este caso se trató de recuperar ganado vacuno robado en la zona de Huanqueros y de otras estancias que quedaron en el camino de la retirada del "malón”. Según Jesperson, los estancieros siempre iban ellos mismos a este tipo de expedición, nunca mandaban peones o a personas que trabajaban para ellos ya que si se morían tenían la obligación de sostener sus familias por el resto de sus vidas. La expedición se divide en dos y logran crear una emboscada en la cual caen los indígenas que estaban huyendo con el ganado. Durante el ataque matan a un mocoví y Jesperson persigue a otro que al final logra escaparse. Luego hay un relato sobre la tortura y ejecución del cacique Takó por parte del colono Hauptman.

"Imaginen nuestra sorpresa cuando nos dimos cuenta que uno de los nuestros estaba involucrado en algo que me paralizó de terror. Un indio estaba atado a un tronco de árbol carbonizado. Sus muñecas estaban atadas, de tal modo que abrazara el tronco. Hasta sus piernas estaban atadas. Un sonido de "chisporoteo" llegó a mis oídos, como cuando se rompen hojas. Hauptman estaba detrás de la espalda del indio, ocupado con algo que lo tenía tan concentrado, que parecía no darse cuenta de nuestra llegada. Rápidamente con su cuchillo hace una incisión horizontal y dos verticales en la piel arriba de los omóplatos, ésta se dobla lo suficiente como para ser agarrado y luego con un tirón y un sonido espantoso queda colgando del lomo una tira de piel. La espalda entera ya estaba destrozada... (Jesperson 1943: 92-93)."'16

Luego del incidente Hauptman es llevado a "juicio" por el comisario de frontera, en el cual justifica su crueldad acusando el cacique muerto de haber matado y mutilado a toda su familia. De esa manera queda absuelto de cualquier condena. En la frontera claramente no se aplicaba el Estado de derecho, en la práctica se juzgaba a un hombre por la legitimidad de sus acciones de acuerdo a la moralidad del grupo presente en el "juicio". La participación de Jesperson en esta expedición, en la cual se produce la tortura y cruel asesinato del cacique Takó, casi le cuesta la vida cuando sale un año más tarde en 1916 a cazar garzas para luego comercializar su plumaje. El resto del libro trata la manera en que los indígenas buscan vengar a su querido cacique y cómo con la ayuda de Macua Jesperson logra escaparse antes de que lo ejecuten.

${ }^{15}$ En el relato de Jesperson aparece la figura de "gränskomissarie" que podría traducirse como "comisario de frontera", posiblemente un integrante de la Policía Fronteriza del Chaco y Formosa, fuerza de seguridad de transición entre el ámbito militar a civil que solo existió entre 1911 y 1914 con sede en El Chorro (Beck 1994). 


\section{Colonización en el Pilcomayo del Medio previa a la Guerra del Chaco}

Durante la década de 1920 y gran parte de 1930 Jesperson dividía su tiempo entre dos proyectos productivos en la zona del Pilcomayo del medio, uno en Argentina y el otro en una zona que actualmente pertenece a Paraguay pero que fue militarizada por Bolivia a principios del siglo XX y luego disputada con Paraguay durante la Guerra del Chaco. Es decir, Jesperson se movía en un territorio donde actuaban y tenían intereses tres Estados Naciones diferentes. Desde 1921 administró su propia estancia y plantación de algodón llamado Campo Luminoso ubicada en las cercanías de Las Lomitas, en el Territorio Nacional de Formosa y entre 1922 y 1933 era contratado por la firma financiera porteña Casa Torre para administrar un proyecto de colonización de una franja de la costa norte del Río Pilcomayo, que se encontraba al noroeste de su estancia, a cuatro días de cabalgata.

Sus esfuerzos por poblar este área de un millón de hectáreas quedan plasmados en su segundo libro En Svensk Caballero vid Pilcomayo (Un Caballero a orillas del Pilcomayo), publicado en 1942. El libro trata de los conflictos que tiene Jesperson con los militares bolivianos, por los cuales es acusado de ser espía paraguayo, acusación que lo lleva a la cárcel y luego de un largo tiempo consigue demostrar su inocencia. Aunque esta es la historia principal del libro aquí trataremos específicamente lo que dice sobre la historia de la adquisición de las tierras por la Casa Torre y la estrategia de colonización empleada por Jesperson. En este caso es posible cotejar algunos relatos con el siguiente material de archivo hallado en el fondo Jesperson en Lund; fotografías, copias de cartas a Fortin Muñoz y Esteros, mapa del Gran Chaco y Bolivia oriental del Ing. Torre de 1921 y el Informe del año ganaderil 1931-1932 firmado por Jesperson que incluye un mapa dibujado a mano con referencias detalladas de caminos, estancias, pueblos, fortines y nombre de cada lote y condiciones del terreno.

La zona de colonización estaba ubicaba al norte de la actual frontera entre Argentina y Paraguay entre los paralelos $24^{\circ}$ y $22^{\circ}$ de latitud sur y los meridianos $60^{\circ}$ $15^{\prime}$ y $62^{\circ} 15^{\prime}$ "de longitud oeste. El Río Pilcomayo constituía el límite austral de la zona. Cuando Jesperson emprende el proyecto existía solo un camino a lo largo del río que conectaba los cuatro fortines bolivianos, Ballivián, Linares, Magariños y Esteros. Entre el primer fortín Ballivián ubicado en el oeste y el último Esteros en el este la distancia era de $250 \mathrm{~km}$. Si miramos el mapa confeccionado por Jesperson (figura 1) pareciera que el fortín Esteros se encuentra dentro de la zona de colonización.

El Ejército boliviano fue la primera institución armada en tener una presencia efectiva en el Pilcomayo del medio. Luego de la fundación de los pueblos de D'Orbigny (1904) y Villamontes (1905) el gobierno boliviano comenzó a establecer una línea de fortines río abajo; primero los fortínes Guachalla ${ }^{17}$ en 1905-1906 y Ballivian en 1906, y luego en 1915 los fortines Linares, Magariños y Esteros y posteriormente varios otros al interior del territorio al acercarse el inicio de la Guerra del Chaco (Morel, 2015; Gordillo y Leguizamón, 2002). Hay diferentes posturas sobre el objetivo de la fundación de

${ }^{17}$ El Fortín Muñiz actualmente se llama Coronel Diaz y donde estaba ubicado el fortín Guachalla actualmente hay una localidad que se denomina Pedro Peña (Fritz 1997). 
estos fortines. Mientras Capdevila señala que tenían funciones de proteger a los colonos frente a la peligrosidad de las tribus chaqueñas Gordillo y Leguizamón (2002) observan que sus fundaciones no necesariamente eran acompañadas por una colonización civil.

Según Jesperson (1942: 26), el fortín Esteros era el principal núcleo poblacional de la zona y sede del comandante en jefe de las tropas bolivianas en el Chaco Boliviano. Se trataba de una construcción bastante robusta, rodeado con una valla de tierra y alambre de espino, al cual había dos entradas, la principal era a través de una torre (Figura 2). El edificio principal, donde los oficiales tenían sus expediciones y viviendas, era de unos setenta y cinco metros de largo por seis metros de ancho. Generalmente la guarnición constaba de cerca de 100 soldados. Existía además un pueblo a lado del fortín con una población civil de 100 personas. Estos datos concuerdan con lo señalado por Capdevila (2010) que, aunque la presencia militar boliviana en el Chaco era significante, era muy limitada en números.

También informa Jesperson que vivían aproximadamente 4000 indígenas "chunipis"18 alrededor de Esteros en la zona destinada a la colonización y que existía una misión, dirigida primero por el padre Rose y luego por "Monseñor Breuer", que se ocupaban de su evangelización. A diferencia del interés que muestra por la descripción etnográfica de sociedades indígenas en la compilación de Munthe (1943) y en el guión del film Tras los senderos indios del Pilcomayo no hemos encontrado en el corpus estudiado ni fotografías ni relatos sobre la sociedad nivaclé con la cual tuvo contacto cuando administró la colonización entre 1922 y 1933. Con respecto a los "chunipis" cuenta que "estos indios han sido domesticados originalmente por mí, es decir, los acostumbré a los hombres blancos y los hice un poco más civilizados. Por su bien, también le concedí tierra a una misión católica dirigida por un alemán, Monseñor Breuer (Jesperson,1942: 25-26)."

Sabemos gracias a las investigaciones de Morel (2015) y Fritz (1997 y 1999) que, a partir de la creación de la Prefectura Apostólica del Pilcomayo (PAP) en 1924, los misioneros alemanes de la congregación de los Oblatos de la Inmaculada María respondieron al pedido del gobierno boliviano estableciendo misiones del lado derecho del Río Pilcomayo en las cercanías de los fortines existentes. Los primeros misioneros oblatos a llegar fueron los padres José Rose, Enrique Breuer, Enrique Lambertz y los hermanos José Kremer y Federico Widman. La administración militar boliviana insistió en que Rose fundara en 1925 la primera misión en Esteros, el puesto boliviano más avanzado y no en Villa Manzo como estuvo previsto (Fritz, 1997). Como señala Morel (2015) se puede entender la creación de la PAP como una decisión política tomada por el gobierno boliviano para frenar el avance de las misiones protestantes pedidas por el gobierno paraguayo.

\footnotetext{
${ }^{18}$ Esta sociedad indígena es conocida en las fuentes con diferentes nombres. Jesperson los llaman Chunipí o Chunupí, Nordenskiöld y Métraux los llamaban Ashlushlay, en otras fuentes como las de los misioneros oblatos y algunas publicaciones académicas se utiliza la denominación Chulupí, y se autodenominan actualmente Nivaclé.
} 
En este contexto de militarización y posterior misionalización se desarrolla el proyecto de colonización administrada por Jesperson. Hasta el momento no hemos encontrado bibliografía sobre la existencia de iniciativas y políticas de colonización empleadas por el gobierno boliviano para la zona del Pilcomayo que aquí nos ocupa. Si estudiamos el mapa del Gran Chaco y Bolivia oriental realizado por el Ingeniero Torre en 1921 (Figura 3), podemos observar que varios de los nombres de las propiedades que se extienden desde el Río Paraguay al oeste al interior del Chaco boreal, corresponden a firmas y inversores que compraron sus tierras al gobierno paraguayo, enmarcado en el proceso de latifundización y privatización de los territorios chaqueños disputados entre Paraguay y Bolivia. El caso más notable es la vasta extensión de tierra que aparece en el mapa bajo el nombre de "Sociedad anónima "Carlos Casado limitada", siendo Carlos Casado delAlisal uno de los más importante latifundistas del Chaco paraguayo. El sistema latifundista fue instaurado a través de la privatización del Chaco boreal ya durante el siglo XIX por parte del gobierno de Paraguay, como una de las salidas adoptadas para enfrentar la crisis generalizada producida por la guerra de la Triple Alianza (Dalla Corte 2007). Bolivia, a diferencia de Paraguay, fue menos activo en este proceso de ocupación del Chaco mediante la venta de tierras fiscales, tal vez, dado el interés del empresariado boliviano en el Beni (Dalla Corte, 2007). Volviendo al mapa de 1921, sostenemos que los lotes trazados en blanco a la ribera del Pilcomayo corresponden a tierras que habían sido vendidas por el gobierno de Bolivia o que éste está buscando colonizar. Sobre la política de colonización empleada por parte del gobierno boliviano Jesperson (1942: 18) escribe lo siguiente:

“...el gobierno boliviano había vendido parcelas de veinte mil hectáreas al norte del río Pilcomayo. Cada persona podía solamente comprar una parcela bajo la condición que dentro de un cierto número de años ésta debía estar poblado con veinte familias, es decir, una familia por cada mil hectáreas. Para que esto fuese factible de llevar a cabo, el gobierno se comprometió a hacer accesible la zona, mediante la construcción de caminos, pero como nunca se cumplió con esta clausula, los propietarios tampoco se dieron prisa en traer colonos."

En la década de 1920 varias de estas parcelas, que habían sido originalmente destinadas a diferentes compradores, habían sido adquiridas por la Casa Torre de Buenos Aires, creando así un latifundio en el Chaco Boreal comparable con el de Carlos Casado. Según Jesperson, la creación de este latifundio se hizo posible por el estrecho vinculo que existía entre el gobierno boliviano y la firma financiera porteña que se remontaba a la ayuda económica que esta última había brindado a Bolivia cuando luego de la Guerra de Acre, financiando el retorno a su país de muchos soldados bolivianos varados en la Amazonía vía Rio de Janeiro y Buenos Aires. Varios funcionarios bolivianos se habían convertido en propietarios de grandes extensiones de estas tierras a través de testaferros y de esta manera se le ofreció a la firma comprar una gran área contigua (Jesperson, 1942:18). Jesperson fue contratado por la firma primero para evaluar el valor y las 
características de las tierras antes de la compra y luego como administrador local de colonización y apoderado de la Casa Torre. Su responsabilidad como administrador incluía garantizar la accesibilidad a los lotes mediante picadas y caminos y localizar lugares adecuados para las viviendas, preferiblemente cerca a un cuerpo de agua o en un sitio donde fuera posible excavar un pozo de agua dulce.

Basado en su conocimiento de las características del ambiente y del suelo, Jesperson buscó en primer lugar atraer, para colonizar las tierras, criollos argentinos que eran propietarios de ganado vacuno. Una colonia basada en la actividad ganadera tenía mejores perspectivas que una basada en la agricultura por la presencia de muy buenas zonas de pastoreo (de pasto crespo) que abundaban a pesar de periodos largos de sequía. Sin embargo, para disminuir la necesidad de importar harina, cereales y maíz, se fomentó la contratación por parte de los propietarios de ganado de familias hábiles en el cultivo de la tierra. De esta manera, era posible producir en una escala muy pequeña, maíz, calabaza, batata y mandioca para el autoabastecimiento de los colonos. Así cada lote tenía dos en lugar de una familia. En el mejor de los casos, se conseguía una tercera familia dedicada a la producción de lácteos (Jesperson, 1942: 24-25).

Como se observa en la historiografía de la frontera del Pilcomayo, antes de la Guerra del Chaco había criollos que desde el territorio argentino comenzaron a cruzar el río Pilcomayo y a poblar con su ganado territorio boliviano con el consentimiento de las autoridades de los fortines (Torres, 1975; Mendoza y Maldonado, 1995 en Gordillo y Leguizamón, 2002). Es posible que varios de estos criollos hayan sido colonos del proyecto administrado por Jesperson.

\section{Palabras finales}

Con este trabajo he buscado dar a conocer y realizar una primera valoración de algunas fuentes inéditas e editas, hasta ahora poco conocidas en la historiografía del Chaco por estar escritas en sueco y no contar con una traducción al castellano o inglés. Aquí hemos explorado su valor especialmente en cuanto a las relaciones interétnicas en el norte del Chaco Austral a comienzos del siglo XX y prácticas de colonización en el sur del Chaco Boreal en las décadas 1920-1930, zonas y tópicos para las cuales existen pocas otras fuentes que abarcan esos mismos períodos. De esta manera, describí y contextualice algunos sucesos descritos por Jesperson en estas zonas de frontera sin, por eso, perder de vista la mirada, intenciones e intereses del emisario y el público al cual eran destinadas sus memorias publicadas en 1940.

Tanto la valorización de las expediciones junto a criollos y gauchos, expresado en la obra sobre sus primeros años en el Chaco Austral, como su adquisición y puesta en práctica de ese conocimiento local y territorial para crear y mantener su propio emprendimiento productivo algodonero y para luego en el Chaco Boreal llevar adelante la administración de una colonización a gran escala en la cual era imprescindible generar las condiciones que permitiesen a los colonos desarrollar actividades productivas, nos llevan a pensar que el transitar se hace posible gracias a un habitar y un constante aprendizaje del ambiente y sus actores y, a la vez, que el desplazamiento por el territorio 
es un factor crucial para habitar el suelo americano de un modo que se basa en la productividad de la tierra. En este sentido, vemos cómo el conocimiento práctico que permite llevar a cabo una colonización se va adquiriendo en etapas a lo largo de una vida a través de diferentes situaciones y experiencias en el territorio. A partir de un repertorio de prácticas aprendidas se seleccionan las más adecuadas para el caso específico de colonización. La puesta en práctica y las formas que toman los proyectos de colonización en zonas de frontera estarían entonces condicionadas por las trayectorias de las personas que emprenden tales prácticas in situ.

En este sentido, podríamos resaltar posibles diferencias y similitudes entre estas narraciones impregnadas de un conocimiento territorial profundo del habitar con, por ejemplo, los relatos de viajeros. La diferencia podría radicar en el tipo de acercamiento y convivencia que tienen los emisarios con la realidad americana relatada y las similitudes en la posición e identidad de extranjería o lejanía cultural desde el cual se fabrica el relata cuyo lenguaje es condicionado por el publico destinatario, muchas veces culto, urbano y/o incluso extranjero.

Finalmente queremos advertir que este artículo solo consta de un primer paso en el estudio del corpus textual y visual dejado atrás por este colonizador y explorador del Gran Chaco. Dada la riqueza y abundancia de la documentación de archivo relacionada a las practicas de colonización de Jesperson en el Pilcomayo del Medio, se justificaría realizar otro trabajo en el cual se profundizara en las diferentes etapas y detalles del proyecto a la vez que las cambiantes posturas de los militares bolivianos con respecto a la condición de extranjería tanto de los colonos argentinos como el propio Jesperson, en un contexto de crecientes tensiones con Paraguay. También sería de interés cotejarlo con un relevamiento y análisis de documentos oficiales de la época emitidos por el gobierno Boliviano.

\section{Referencias bibliográficas}

Anónimo, 1945. "Jesperson, Mauricio" En Harnesk, P. (Ed.). Vem är vem? Stockholms delen. Stockholm, Vem är Vem Bokförlag.

Anónimo. 1940. "Mauricio Jesperson” En: Skåningar i Stockholm Malmö, Skånetruckeriet.

Altman, A. 2011. "Historia y conversión: el evangelio entre los mocoví del Chaco Austral" En: Runa, Vol.32, N² 2 .

Alvarsson, J.-Å. 2002. "Till Bolivias indianer...” Berättelsen om Svensk Pingstmission i "Sydamerikas skogstrakter". Örebro: MissionsInstitutet-PMU och Pingströrelsens Informationscentrum.

Alvarsson, J.-Å. 1982. Indianeld. Avesta: A.B.M. - tryck AB.

Anderås, P. 1961. Boliviafarna berätta, Örebro: Evangelipress.

Beck, H. 1994. Relaciones entre blancos e indios en los territorios nacionales de Chaco y Formosa, 1885 -1950. Resistencia, Chaco, Instituto de Investigaciones Geohistóricas. 
Boccara, G. 2001. "Mundos nuevos en las fronteras del Nuevo Mundo". En: Nuevo Mundo, Mundos Nuevos. No. 1.

Bossert, F. y Siffredi, A. 2011 Las relaciones interétnicas en el Pilcomayo medio: la guerra indígena y sus transformaciones (1882-1938), Población \& Sociedad, Vol. $18, \mathrm{~N}^{\mathrm{o}} 1, \mathrm{pp} .3-48$.

Briones, C. 2005. "Formaciones de alteridad: contextos globales, procesos nacionales y provinciales", en Briones, C. (ed.): Cartografías argentinas, Buenos Aires, Antropofagia, pp. 11-44.

Capdevila, L. 2010. "Los fortines del "desierto": ventanas abiertas sobre las relaciones indígenas/militares," En Luc Capdevila, Nicolas Richard, Pablo Barbosa (Eds.) Los hombres transparentes. Indigenas y militares en la guerra del Chaco, 19321935, pp. pp. 83-119: Instituto de misionología (UCB), col. Scripta Autochtona/ Historia Indígena de las Tierras Bajas.

Cernadas, C. C. 2011. La misión pentecostal escandinava en el Chaco argentino. Etapa formativa: 1914 - 1945. Memoria americana 19 (1).

Citro, S. 2006. Tácticas de invisibilización y estrategias de resistencia de los mocoví santafesinos en el contexto postcolonial. Indiana 23:139-170.

Dalla Corte, G. 2007. Redes y organizaciones sociales en el proceso de ocupación del Gran Chaco. Revista de Indias LXVII (240).

Dalla Corte, G y Vazquez Recalde. 2011. La conquista y ocupación de la frontera del Chaco entre Paraguay y Argentina. Los indígenas tobas y pilagás y el mundo religioso en la Misión Tacaaglé del Río Pilcomayo (1900-1950). Barcelona, Publicacions i Edicions de la Universitat de Barcelona

Dosztal, I. 2016. Alexandra Colony: Resiliencia en el norte de la Provincia de Santa Fe (1866-1904), Argentina. En: Estudios Fronterizos, 17(34), 117- 136, https://doi. org/10.21670/ref.2016.34.a07

Drougge, L. 1991. Caballero. Stockholm, Carlssons

Fritz, M. 1997 “Nos han salvado”. Misión: ¿Destrucción o salvación? Quito: AbyaYala,

Fritz, M. 1999 Pioneros en El Chaco: misioneros oblatos del Pilcomayo. Mariscal Estigarribia, Vicariato Apostólico del Pilcomayo.

García Jordan, P. 2001. Cruz y arado, fusiles y discursos. La construcción de los Orientes en el Perú y Bolivia, 1820-1940, Lima, Instituto Francés de Estudios Andinos (IFEA), Instituto de Estudios Peruanos (IEP).

Ginzburg, C. 2010. "Introducción" y "Pruebas y posibilidades", En: El hilo y las huellas. Lo verdadero, lo falso, lo ficticio, Buenos Aires, FCE

Giordano, M. y Gustavsson, A. 2013. "Entre la narrativa de viaje y el discurso etnográfico. La primera filmografía en el imaginario del indígena chaqueño" en Giordano, Mariana, Luciana Sudar Klappenbach y Ronald Isler Duprat (Ed.) Memoria e Imaginario en el Nordeste Argentino. Escritura, oralidad e imagen. Prohistoria. Rosario. 
Gordillo, G. 2001. "'Un Rio tan salvaje e indómito como el indio toba': una historia antropológica de la frontera del Pilcomayo”. En: Desarrollo Económico, Vol. 41, No. 162 (Jul. - Sep.), pp. 261-280.

Gordillo, G y Leguizamón, J. M. 2002. El río y la frontera: movilizaciones aborígenes, obras públicas y MERCOSUR en el Pilcomayo. Buenos Aires, Editorial Biblos.

Greca, V. 2009. "Un proceso de rebelión indígena Los mocovies de San Javier en 1904". En: Avá Nr.15, pp. 333-349.

Gustavsson, A. y M. Giordano. 2013. "The Pilagá of the Argentine Chaco through an exoticizing and ethnographic lens: The Swedish documentary film Following Indian Trails by the Pilcomayo", En: Journal of Aesthetics and Culture, Vol.5 ISSN 2000-4214, URL: http://dx.doi.org/10.3402/jac.v5i0.21562

Gustavsson, A. y M. Giordano. 2012. "El documental etnográfico de Wilhelm Hansson y Mauricio Jesperson. Registros del indígena chaqueño para un público europeo” Actas III Congreso Internacional de la Asociación Argentina de Estudios de Cine y Audiovisual Universidad Nacional de Córdoba.

Jesperson, M. 1943. I Vildmarkens Våld, Stockholm, Norstedt.

Jesperson, M. 1942. En Svensk Caballero vid Pilcomayo, Stockholm, Norstedt.

Kung, A. 1977. Boliviafarna. Stockholm, Normans bokförlag.

López, Alejando M. 2009. La Virgen, el Árbol y la Serpiente. Cielos e Identidades en comunidades mocovíes del Chaco. Tesis de Doctorado, Universidad de Buenos Aires.

Lindberg, C. 1996. Erland Nordenskiöld - ett indianlif. Stockholm, Natur och Kultur.

Mapelman, V. y Musante, M. 2010 "Campañas militares, reducciones y masacres. Las prácticas estatales sobre los pueblos originarios del Chaco”. En Historia de la crueldad argentina: Julio A. Roca y el genocidio de los pueblos originarios. Buenos Aires, Editorial El Tugurio.

Mendoza, M y M.E. Maldonado. 1995. Poblamiento y colonización criolla del noroeste del Territorio Nacional de Formosa entre los años 1875 y 1925. M.S.

Morel, M. 2015. "Bosquejo de demografía chaqueña: chulupí y misioneros oblatos en el Pilcomayo, 1924-1940," En Lorena Córdoba e Isabelle Combés (eds.) El corazón de América del sur (Vol.1). Santa Cruz de la Sierra: Museo de Historia, Universidad Autónoma Gabriel René Moreno.

Munthe, C. Ed. 1943. Chacofarare berätta. Göteborg, Hugo Gerbers Förlag.

Nordenskiöld, E. 1926 (1910) Indianliv i El Gran Chaco, Sydamerika.Stockholm: Åhlén \& Åkerlunds

Pratt, M.L. (2011) Ojos imperiales, Argentina, Fondo de Cultura Económica

Richard, N. Editor. 2008. "Presentación" En: Nicolas Richard (Comp.) Mala Guerra: Los indigenas en la Guerra del Chaco (1932-1935). Asunción \& Paris: Museo del Barro, ServiLibro \& CoLibris.

Rosen, E. v. 1921. Bland indianer, Forskningar och äventyr $i$ Gran Chaco Stockholm: Albert Bonniers förlag

Rydén, S. 1936. Chaco. En resa bland fornlämningar och Indianer i argentinska och bolivianska Chaco. Göteborg, Förlag- aktiebolaget Västra Sverige. 
Gustavsson. Prácticas de exploración y colonización. Relatos de Mauricio Jesperson sobre el Gran Chaco durante...

Spota, J. C. 2009. Los fortines en la frontera chaqueña (1862-1884). Un enfoque desde la antropología histórica en relación con la teoría de las organizaciones. Memoria Americana 17 (1):85-117.

Tamagno, L. 2001. Los tobas en la casa del hombre blanco. Identidad, Memoria y utopía. La Plata, Ed. Al Margen.

Torres, M. I. 1975. Ingeniero Guillermo Nicasio Juárez y los parajes del oeste de Formosa. Formosa, Ediciones tiempo de hoy. 


\section{Lista de figuras}

1. Mapa trazado por Jesperson publicado en En Caballero vid Pilcomayo (1942) con el siguiente epígrafe: "El Gran Chaco Boliviano. El área encuadrada bajo el título Trasfonden es la que fue colonizada por Don Mauricio. La línea de puntos representa el camino que emprendió Don Mauricio para llegar a La Paz" (Traducción mía).

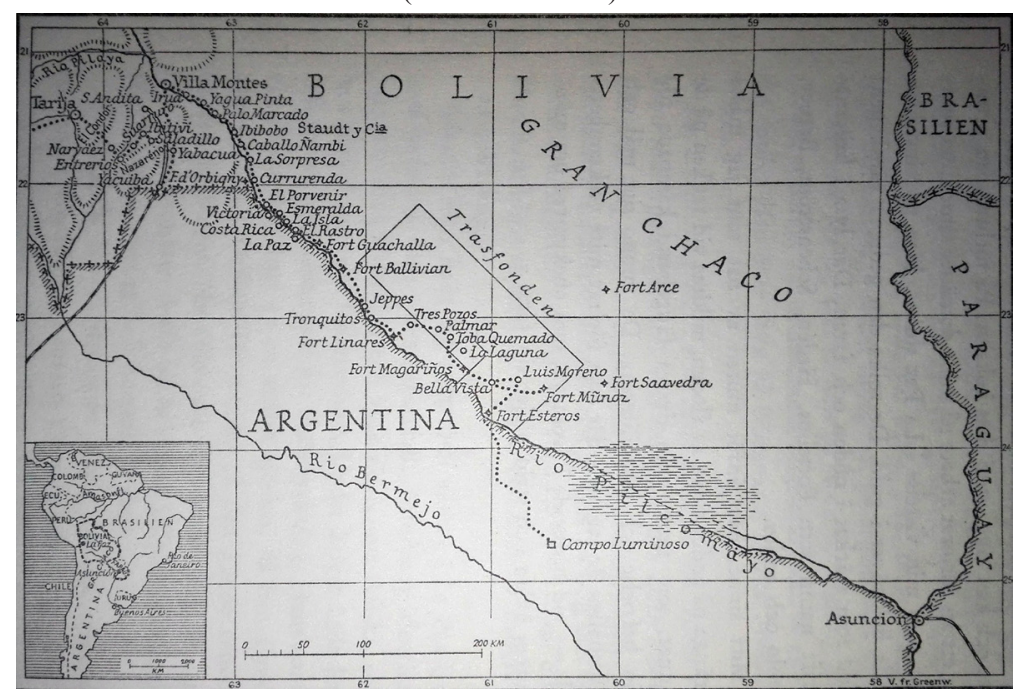

2. Torre de guardia, Fortín Esteros, 1920. Fondo Jesperson, Universidad de Lund.

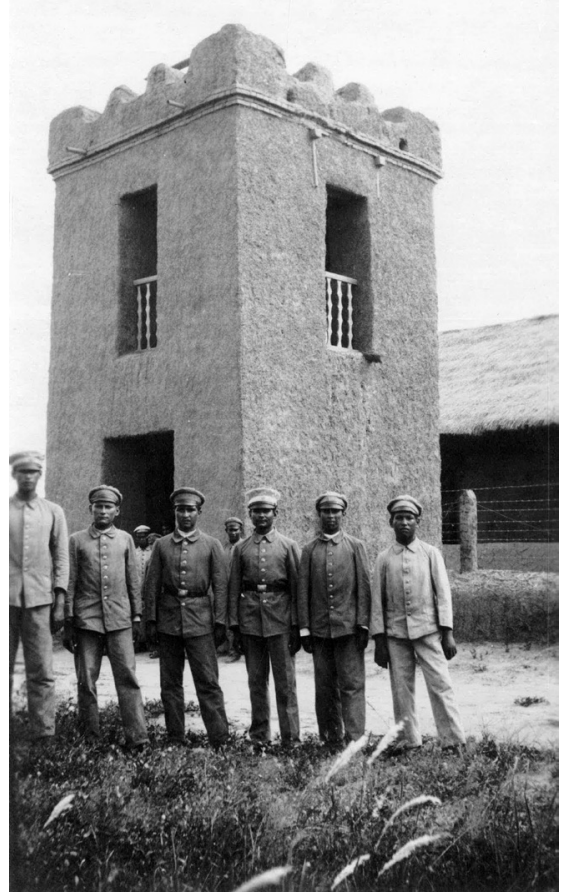




\section{ARTÍCULOS}

Gustavsson. Prácticas de exploración y colonización. Relatos de Mauricio Jesperson sobre el Gran Chaco durante...

3. Mapa del Gran Chaco y Oriente de Bolivia 1921. Fondo Jesperson, Universidad de Lund.

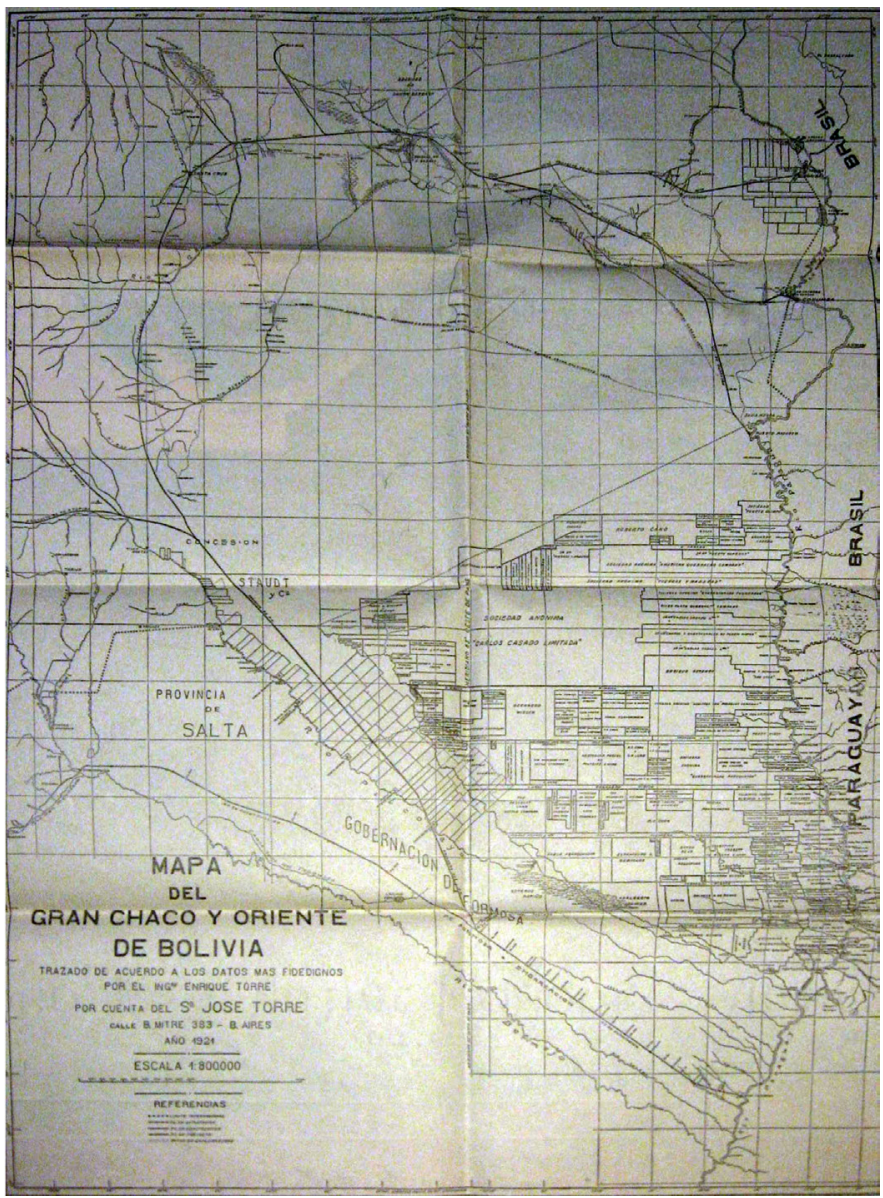

